\title{
Erratum to: Intrinsic variability of latency to first-spike
}

\author{
Gilles Wainrib • Michèle Thieullen • \\ Khashayar Pakdaman
}

Published online: 29 October 2011

(C) Springer-Verlag 2011

\section{Erratum to: Biol Cybern (2010) 103:43-56}

DOI 10.1007/s00422-010-0384-8

In the original publication of this article, the names of the authors were erroneously published in reverse order.

The correct names are Gilles Wainrib, Michèle Thieullen and Khashayar Pakdaman.

The online version of the original article can be found under doi: 10.1007/s00422-010-0384-8.

G. Wainrib (凶)

Centre de Recherche en Epistémologie Appliquée, UMR 7656,

Ecole Polytechnique, CNRS, Paris, France

e-mail: gilles.wainrib@polytechnique.org

M. Thieullen

Laboratoire de Probabilités et Modèles Aléatoires (LPMA),

UMR 7599, CNRS, Univ. Paris VI, Paris VII,

Paris, France

e-mail: michele.thieullen@upmc.fr

K. Pakdaman

Institut Jacques Monod (IJM), UMR 7592, CNRS, Univ. Paris VII,

Paris VI, Paris, France

e-mail: pakdaman@ijm.univ-paris-diderot.fr 